\title{
Эффект насыщения выходной мощности волоконных Er-Yb лазеров
}

\author{
А.А. Сурин ${ }^{1, *}, \underline{\text { H.В. Коваленко }}^{1,2}$ \\ ${ }^{1}$ НТО “ИРЭ-Полюс”, Фрязино \\ ${ }^{2}$ Московский Физико-Технический Институт (ГУ), Москва \\ *E-mail: aSurin@ntoire-polus.ru
}

DOI: 10.31868/RFL2020.63-64

Одним из эффектов, ограничивающих выходную мощность излучения, которую можно получить в лазерах на основе эрбиевых и иттербий-эрбиевых активных сред является насыщение, теоретически предсказанное в работах $[1,2]$. В обеих работах эффект объясняется существованием «узкого места», ограничивающего передачу возбуждения накачки к рабочему уровню. В работе [1] сказано, что для чисто эрбиевых сред таким местом является переход между уровнями ${ }^{4} \mathrm{I}_{11 / 2} \rightarrow{ }^{4} \mathrm{I}_{13 / 2}$. Для иттербий-эрбиевых сред в более общем виде ограничением является скорость передачи возбуждения от $\mathrm{Yb}$ к уровню ${ }^{4} \mathrm{I}_{13 / 2} \mathrm{Er}$ [2].

В данной работе впервые, по мнению авторов, представлены экспериментальные наблюдения данного эффекта в лазере на $\mathrm{Yb}-\mathrm{Er}$ волокне, a также теоретически выведена формула для оценки мощности насыщения, расчёт по которой согласуется с экспериментальными результатами.

На рис.1 приведена оптическая схема эксперимента. Было собрано 3 лазера, по представленной оптической схеме, состоящей из иттербий-эрбиевого активного волокна, волоконных брэговских решеток и волоконного поляризатора. Весь оптический тракт собран на волокне, поддерживающем поляризацию. Параметры используемых активных волокон приведены в таб.1. Накачка лазеров производилась на длинах волн 1065 и 1070 нм одномодовым излучением в сердцевину активного волокна.

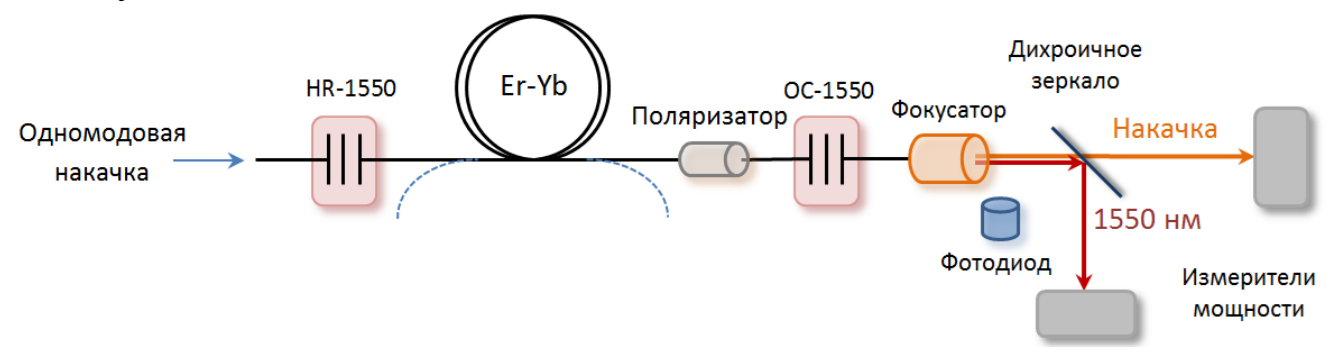

Рис. 1. Оптическая схема лазера на 1550 нм.

На рис.2 представлена ватт-ваттная характеристика лазера с активной схемы длиной 5м. Мощность сигнального излучения 1550 нм при малых мощностях накачки возрастает с дифференциальной эффективностью $27 \%$ и выходит на насыщение при 15 Вт. Мощность излучения 1065 нм на выходе растет при мощности накачки больше 50 Вт линейно с эффективностью 50\%. Эффект насыщения наблюдается в каждом из приведенных экспериментов, в таблице 1 приведены мощности насыщения для каждого лазера.

Выходная мощность лазерной системы ограничена, так как количество ионов эрбия, участвующих в генерации, ограничено и существует конечное время, за которое ион может получить энергию и передать часть её во внешнюю среду в виде электромагнитного излучения, перейдя при этом обратно в невозбуждённое состояние. 

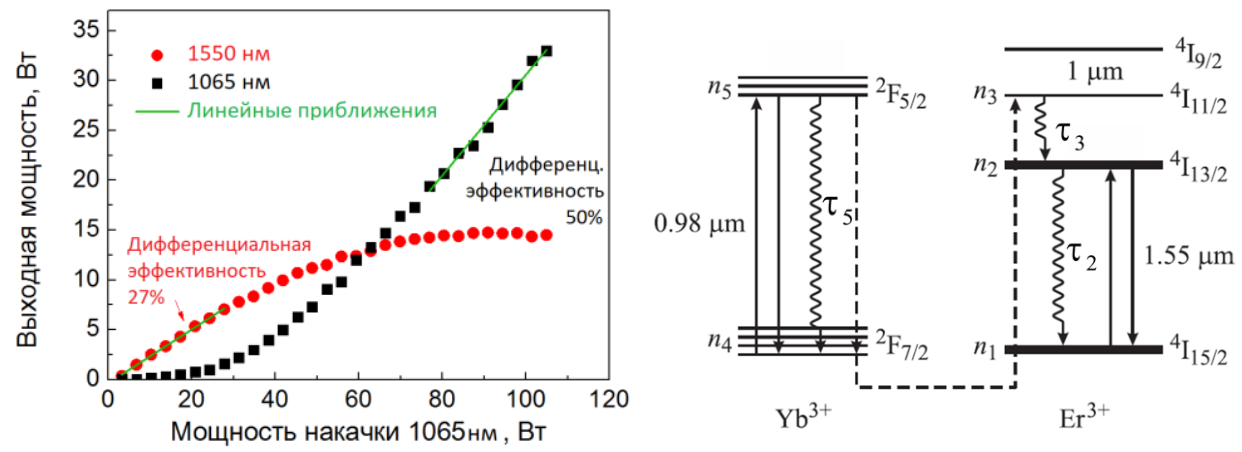

Рис. 2. Зависимость мощности излучения на 1550нм и остаточной мощности накачки на 1065нм от мощности накачки (слева) и схема энергетических уровней в иттербий-эрбиевой активной среде (справа).

Основываясь на предположении, что узким местом генерации является переход ${ }^{4} \mathrm{I}_{11 / 2} \rightarrow{ }^{4} \mathrm{I}_{13 / 2}$ (рис.2), может быть получена формула для мощности насыщения $P_{\text {sat }}$ :

$$
P_{s a t}=\frac{h c}{\lambda_{s}} \frac{N_{E r}}{\tau_{3}}\left(1+\frac{\sigma_{Y b}^{e}}{\sigma_{Y b}^{a}}\left(1+\frac{\sigma_{E r}^{a}}{\sigma_{E r}^{e}}\right)\right)^{-1}
$$

Где $N_{E r}$ - количество ионов эрбия в среде, $\tau_{3}$ - время жизни на уровне ${ }^{4} \mathrm{I}_{11 / 2}$, $\lambda_{s}$ - длина волны сигнала, $\sigma_{E r}^{a}, \sigma_{E r}^{e}, \sigma_{r b}^{a}, \sigma_{r b}^{e}$ - сечения поглощения и люминесценции рабочих уровней эрбия и иттербия соответственно, $h$ постоянная Планка, $c$ - скорость света.

На основе экспериментальных данных и предложенной формулы нами было оценено время жизни уровня ${ }^{4} \mathrm{I}_{11 / 2}$ (таб.1). Видно, что для активных схем с различными количествами ионов эрбия и длиной волны накачки мощности насыщения значительно различаются $P_{\text {sat }}$, однако восстановленные времена жизни $\tau_{3}$, как и должно быть имеют приблизительно одинаковые значения. В мировой литературе данное время для фосфатных стекол сред лежит в диапазоне $1-3$ мкс [1,3].

Таблица 1. Экспериментальные и теоретические результаты

\begin{tabular}{|c|c|c|c|c|c|}
\hline $\begin{array}{c}\text { Длина, } \\
\text { м }\end{array}$ & $\begin{array}{c}\text { Диаметр } \\
\text { жилы, } \\
\text { мкм }\end{array}$ & $\begin{array}{c}\text { Концентрация } \\
\text { ионов эрбия, } \\
\text { ррm }\end{array}$ & $\begin{array}{c}\text { Длина } \\
\text { волны } \\
\text { накачки, } \\
\text { нм }\end{array}$ & $\begin{array}{c}P_{\text {sat }}, \text { Вт } \\
\text { (эксперимент) }\end{array}$ & $\begin{array}{c}\tau_{3}, \text { мкс } \\
\text { (расчёт) }\end{array}$ \\
\hline 4 & 9,1 & 230 & 1070 & 1,7 & 1,53 \\
\hline 6 & 9,1 & 230 & 1070 & 2,5 & 1,56 \\
\hline 5 & 18 & 300 & 1065 & 15 & 1,38 \\
\hline
\end{tabular}

Авторы выражают благодарность руководству НТО «ИРЭ-Полюс» за поддержку данных исследований.

\section{Литература}

[1] R.S. Quimby, Applied Optics, 30 (18), 2546-2552 (1991)

[2] E. Yahel, A. Hardy, Journal of lightwave technology, 21(9), 2044-2052 (2003)

[3] Н.Е. Алексеев, В.П. Гапонцев, М.Е. Жаботинский, Лазерные фосфатные стекла, М.: Наука, 352 c. (1980) 